\title{
DEL HÍBRIDO IMAGINADO A LA REALIDAD CIBERNÉTICA
}

\author{
Àngela Montesinos Lapuente \\ Universitat de València
}

\begin{abstract}
Resumen: En los mundos imaginados, existen seres que no son del universo racional y cuyo aspecto se construye con partes de otros, híbridos. Son pedazos unidos que adquieren unidad, identidad significativa para la sociedad que les da forma. Constituyen parte del mito, de la religión, de la narración. Su creadora es la divinidad, a veces también Dios es híbrido. Pero el humano también juega a la creación a través de la ciencia, el arte y la ciencia ficción. Seres que deberían ser superiores a nosotros, el ciborg, en el mundo físico y en el ciberespacio.
\end{abstract}

Palabras clave: Mitología, híbrido, ciborg, arte, historia del arte, tecnología, cibernética, feminismo.

\section{From the imagined hybrid to the Cybernetic reality}

Abstract: In the imagined worlds, there are beings that are not of the rational universe and whose appearance is built with parts of others, hybrids. They are united pieces that acquire unity, meaningful identity for the society that gives them form. They are part of the myth, of religion, of narration. Its creator is the divinity, sometimes even god is hybrid. But humans also play creation through science, art and science fiction, beings that should be superior to us, the cyborg, in the physical world and in cyberspace.

Key words: Mythology, hybrid, cyborg, art, art history, technology, cybernetics, feminism.

\section{ORÍGENES E HIBRIDACIONES}

En los mundos fantásticos, distópicos, apocalípticos, aparecen con frecuencia seres híbridos. Adquieren una identidad significativa para la sociedad. El ser humano crea, imagina monstruos, los dota de características, inventa narraciones y al final, incluso, cree en ellos.

Son imágenes primigenias, a veces terribles, otras grotescas, pero siempre escalofriantes. Conforman un mundo no controlado, imaginado, que reside en nuestras creencias, en nuestros sueños, en nuestras pesadillas. La hibridación adquiere diferentes e infinitos niveles de profundidad, desde seres polimorfos hasta las leyes de Mendel o la biotécnica.

Data de recepció: 16 de maig de 2019 / Data d'acceptació: 28 d'agost de 2019. 
Hay una realidad en la naturaleza, las alteraciones en los seres vivos por variaciones genéticas, mutaciones, anomalías cromosómicas, o por otras causas relacionadas con el medio ambiente, la contaminación..., la teratología estudia estas cuestiones. Es posible, que, en ocasiones, el hombre primitivo haya visto esta hibridación en animales y en algunas malformaciones de seres humanos, llegando a la conclusión de que estos individuos no se corresponden con el estándar de su especie.

Desde el origen de la humanidad se ha seleccionado animales y plantas, han hibridado diversas especies para conseguir mejores productos. La hibridación ha ido paralela al progreso hasta llegar a casos como el experimento, fracasado, de fecundación de hembras de orangután con esperma humano, realizado a principios del siglo XX por el ruso Ilya Ivanov (Steptoe, P.C. y Edwards, R.G., 1978, 366).

La fusión anatómica, los seres híbridos, son una constante en la historia de la humanidad, reflejados fundamentalmente en el arte y de ahí trasladados a nuestro imaginario, nuestra memoria, nuestro subconsciente individual y colectivo.

El cuerpo mejorado, trastocado, evolucionado, manipulado, se convierte en un ser híbrido.

El término híbrido procede del latín hybrĭda, el diccionario de la RAE nos da diversas acepciones: "Dicho de un animal o de un vegetal: Procreado por dos individuos de distinta especie" y también "Dicho de un individuo: De padres genéticamente distintos con respecto a un mismo carácter".

Pero este ser tiene un origen que viene de la mano de diferentes mundos, de diferentes espacios: del divino, la deidad, lo desconocido y del propio ser humano.

Los seres representados a lo largo de la historia son incontables, no vamos a intentar abarcar ni la ínfima parte de todos y todas ellas en este texto. Y mucho menos querer abarcar los diferentes modos de representación, pero sí vislumbrar un pequeño muestreo significativo en nuestro entorno cultural.

\section{LA DIVINIDAD COMO CREADORA}

La divinidad ha sembrado en nuestro imaginario seres que escapan a nuestra lógica, se representan desde tiempos prehistóricos, pero que llegan hasta nuestros días con la misma fuerza e impacto que cuando fueron fundados.

Seres mitad animal mitad humano, es el caso del centauro, del minotauro, representaciones dispares según las épocas, e incluso diferentes en su significado. Desde los ambientes mágicos y chamánicos en las paredes de las pinturas 
paleolíticas, hasta Picasso en donde genera una comparativa de artista y bestia según la propia mitología griega de personaje híbrido, con cuerpo humano y cabeza de toro, combinando rasgos opuestos: intelecto e instinto, gentileza y concupiscencia, maldad y bondad.

En períodos paleolíticos, el ser humano y el animal convivían en una naturaleza aún pura: "Ambas categorías, animal y humana, no eran entonces distintas. La vida de los cazadores y de los animales constituía un fluido continuo. Era posible a los hombres convertirse en animales y a los animales transformarse en hombres" (Olmos, 2003, 36).

Son seres que deambulan entre una cultura y otra, desde los bellos relieves de la cultura grecorromana a la representación islámica de Buraq mencionada en el Corán, ser mitad humano mitad caballo, quien trasladó a Mahoma de la Tierra al Cielo durante el viaje nocturno.

Para los antiguos griegos estos seres viven en espacio allende el mundo civilizado, en los márgenes, en lo que ellos denominaban eschatiai. (Para una visión de estos seres en el mundo mediterráneo antiguo ver: Izquierdo y Meaux, 2003).

Sirva como ejemplo tres representaciones visuales tan dispares y con significado múltiple respecto a la figura del centauro. El de Lefkandi, hacia el año 900 a.C, la primera representación del mito (Morris, 2007, 422-423); la portada del álbum Ride a Rock Horse de Roger Daltrey (Polydor Records,1975), representación del ídolo, en este caso de nuestra cultura popular, una traslación de la representación de un ser mágico a ídolo de masas; y las películas del afamado Harry Potter (comprende ocho películas producidas en los años 2001, 2002, 2004, 2005, 2007, 2009, 2010 y 2012) en donde podemos observar múltiples recreaciones de mundos ficcionados, imaginados y mitológicos.

En otros casos podemos encontrar la figura del hombre-ciervo reflejada en las superficies cerámicas de época romana, la Terra Sigillata Hispánica, donde el ser híbrido aparece enfrentado a diversos animales (Montesinos, 2002, 9 y 10).

También existen en nuestro imaginario seres híbridos entre diferentes animales como el Mušhuššu, criatura propia de la mitología mesopotámica con elementos de león, animales marinos, serpiente, águila, un ser aterrador creado por la divinidad para introducir en el ser humano un sentimiento de temor. U Oannes, semidios mitad pez mitad humano de las culturas babilónica, sumeria y caldea, este es un ser maravilloso, mágico y que además solía hablar con los humanos y enseñarles buenos modales, letras, matemáticas, etc. (McCall, E., 1999). 


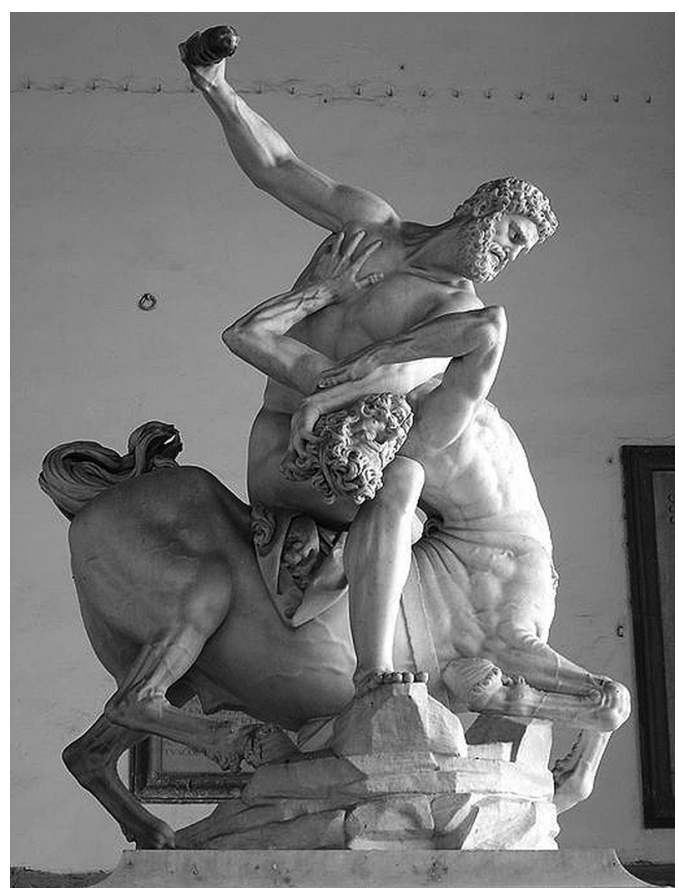

Figura 1. Giambologna. Heracles matando al Centauro. Florencia.

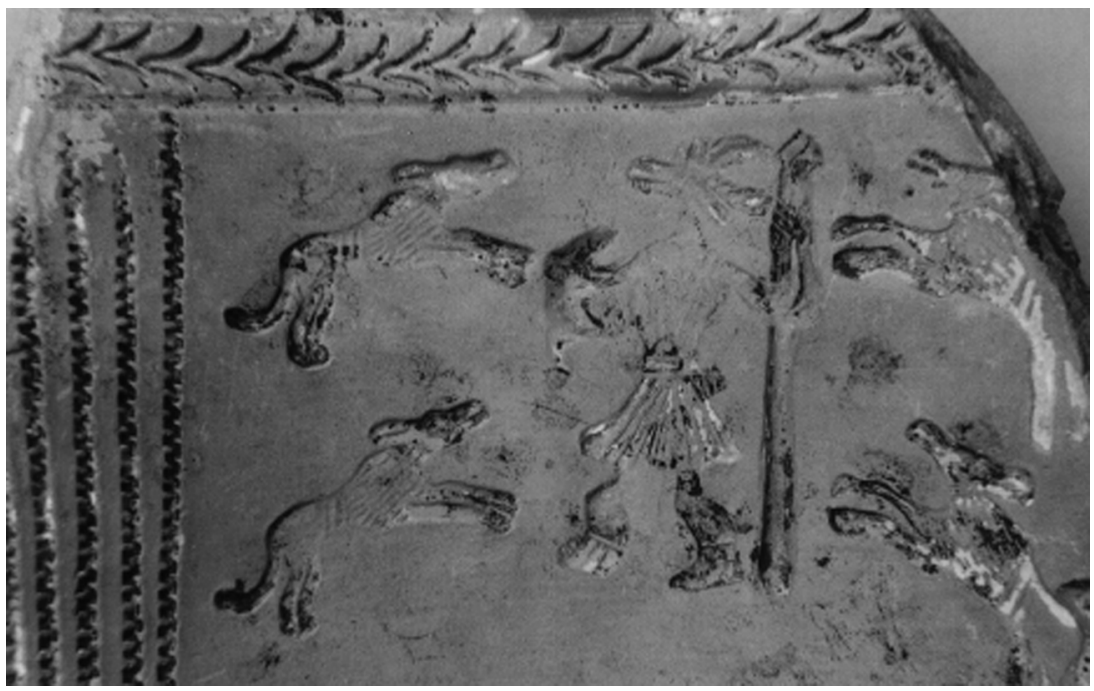

Figura 2. Molde de Terra Sigillata Hispánica de Bronchales (Teruel) representando un hombre-ciervo.

Saitabi. Revista de la Facultat de Geografia i Història, 69 (2019), pp. 109-127 ISSN 0210-9980 DOI: 10.7203/saitabi.69.15944 @() ब€ 
No corren tanta suerte normalmente, como este último, los seres híbridos femeninos. Estos suelen ser harpías, malvadas y aparecen en las historias mitológicas para matar, embaucar, o trastocar de manera negativa los planes del hombre. Ejemplo de ello es Medusa, despiadado monstruo femenino con garras, dientes y piel de serpiente que cualquiera que intentase mirarla quedaba petrificado. Asesinada por Perseo al cortarle la cabeza y que más tarde la utilizará como arma, a cuál de los dos personajes más espeluznantes. No obstante, su imagen se ubicaba en las puertas de las casas como poder protector, incluso su sangre podía resucitar (Para una visión de mitológicos grecorromanos ver: Grimal, P., 1997).

La ambivalencia del terror y la protección son hitos recurrentes entre estos seres que separan al ser humano, físico, en su mundo de realidad y el mundo mágico o divino. Los héroes a través de estos seres sobresalen por su fortaleza y crueldad de sus enemigos, en ese sentido el ser híbrido monstruoso, invencible eleva la posición del héroe al que se enfrenta (Esteban Santos, 2013).

Siguiendo con la estela de la mala mujer, la sirena. Es un ser representado hasta la saciedad por todas las culturas, religiones y épocas. Es un caso muy interesante, sus diferentes significados a lo largo de la historia. Desde la representación con cabeza de mujer y cuerpo de pájaro en la mitología grecolatina, hasta época del medievo. En donde, paulatinamente, cambia su grafía por torso de mujer y cola de pez que embruja a los hombres y solo con la castidad, la honestidad y la virtud se podrán salvar de ellas. Sea como fuere, este ser es manipulador, arrastra al hombre hasta su máximo sufrimiento y a la muerte.

El mito nos describe como Ulises atado al mástil de su barco, es torturado por el canto de sirenas (personaje de la Odisea, poema épico griego atribuido a Homero, s. VIII a.C.). También en la cultura china serán, de nuevo por su canto, quienes dificultan que los marineros las capturen. Incluso una representación tan surrealista como la obra pictórica de René Magritte, La invención colectiva (1934), representa a este ser, pero dentro del particular universo del artista, en donde de-construye la imagen tópica haciéndonos ver cómo de fuerte es nuestro imaginario colectivo.

La imagen de la sirena con el tiempo va dulcificándose iconográficamente, como en el caso del pintor prerrafaelita John Williams Waterhouse con su obra A Mermaid (1901), hasta llegar al nivel de la película de Disney, La Sirenita (The Little Mermaid, Ron Clements y John Musker, 1989) o 1, 2, 3 ...Splash (Splash, Ron Howard, 1984). Pero que no nos engañen estas últimas imágenes, en apariencia amables, ya que esconden otros imaginarios, más espeluznantes si cabe, la representación del mito del amor romántico contemporáneo, con toda su carga heteropatriarcal. Este ser femenino es capaz de dejarlo absoluta- 


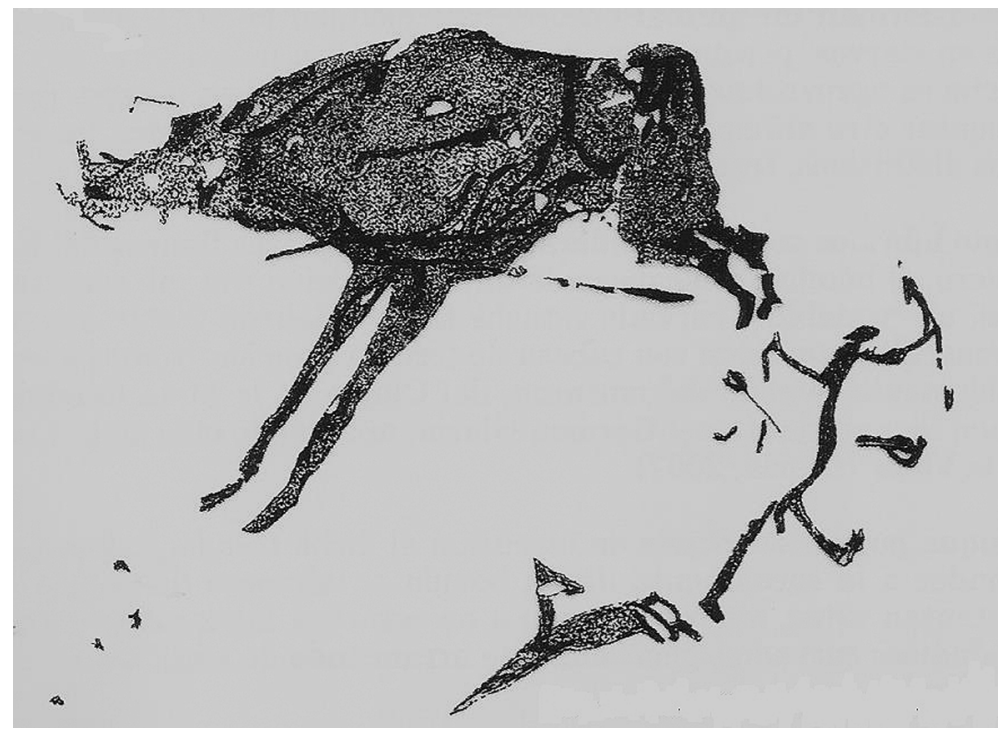

Figura 3. Híbrido de Jalance, dibujo de Aparicio, 2010.

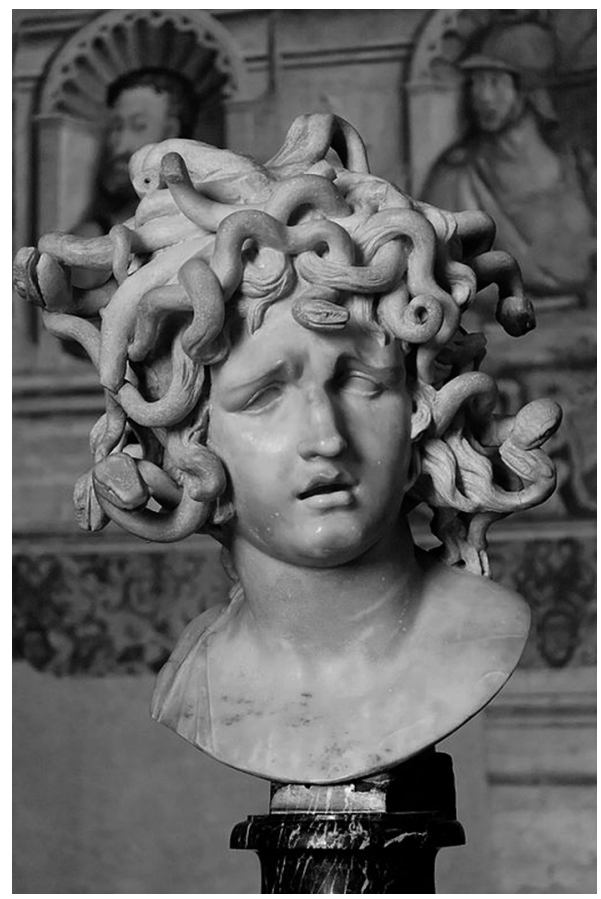

Figura 4. Gian Lorenzo Bernini. Busto de Medusa. Museos Capitolinos.

Saitabi. Revista de la Facultat de Geografia i Història, 69 (2019), pp. 109-127 ISSN 0210-9980 DOI: 10.7203/saitabi.69.15944 (c) (1) 
Figura 5. Estatua funeraria de sirena en el Museo Arqueológico Nacional de Atenas.

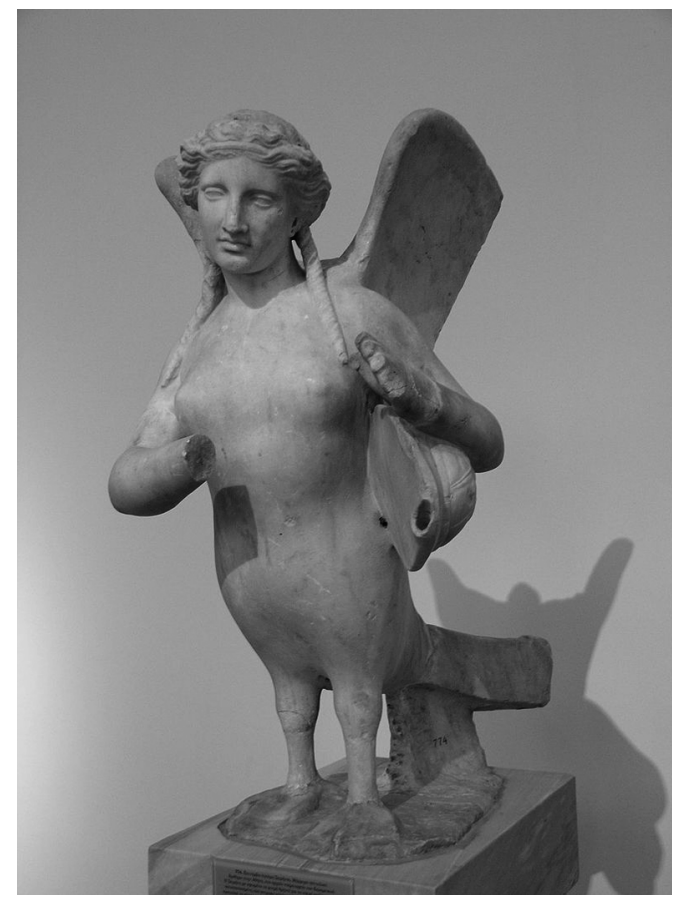

mente todo, incluso su voz, con la que "enamoró" en un principio al príncipe, por el amor de ese mismo hombre, para quedarse con él debe embaucarle, camelarlo y cuantas cosas más.

Y podríamos seguir con una larga lista desde la Antigüedad grecorromana con seres cinocéfalos, hipopodas y entes como la Esfinge, la Quimera, el Minotauro, los Sátiros, el Grifo, Pegaso, Cerbero, Fauno, Basilisco...

Si avanzamos de manera cronológica a lo largo de la historia, nos encontramos con otra visión de estos seres en el mundo de lo maravilloso en el contexto medieval, mostrados para pavor de la colectividad a través de los Bestiarios (Malaxeverría, 1999): la Mantícora (cabeza humana con cuerpo de león y cola de escorpión); el unicornio (como una cabra o con un cuerno sobre la frente), es al igual que Cristo un cuerno de salvación en medio de Jerusalén; el grifo (cuerpo de león, terribles garras, alas y pico de águila) que castiga la temeridad y la codicia, de nuevo, los centauros o la lucha del alma contra las tentaciones del cuerpo. A todos ellos se les da una trascendencia y explicación en relación con la realidad religiosa cristiana, con la salvación. O el denomi- 
nado "prodigio de Rávena", un monstruo que autores desde el siglo XVI están estudiando de manera teratológica. Creado a partir de elementos humanos, pez y ave, relacionando sus deformaciones a fallas morales convirtiéndose en mapa del pecado, en lo que no se debe nadie convertir (Yushimito del Valle, 2010-2011).

\section{DIVINIDADES HÍBRIDAS, EVOLUCIÓN E HISTORIA DEL ARTE}

Pero no solo la divinidad crea seres híbridos, sino que ella misma, en ocasiones, es un ser híbrido. Gran parte de los dioses egipcios son muestra de antiguas creencias animistas, Sejmet, Horus, Bastet, Anubis son algunos de ellos.

Lammasu, divinidad protectora de la mitología mesopotámica, que posee cuerpo de león o de toro, alas de águila, es una figura impactante, como Naga Kanya de la mitología hindú, mujer-ave-serpiente, que significa hija de la serpiente. Pero también en las religiones y mitologías americanas podemos encontrar ejemplos, como es el caso de la serpiente emplumada Quetzalcóatl que representa la dualidad inherente del ser humano.

Todos estos seres, divinidades, calan en el imaginario de todos los tiempos, ya sea para representarlos de manera tradicional, ya sea tomando el sentido mágico, grotesco o inquietante para generar nuevos mundos imaginados.

Los personajes del artista El Bosco (Jheronimus van Aken, 1450-1516), denuncian la vanitas, representa hibridaciones corporales como reflejo de transgresiones carnales. Las ilusiones ópticas del artista Guiseppe Arcimboldo (1527-1593), constituyen esas fusiones, la piel de los rostros son sustituidas por otros elementos como vegetales, libros y otros objetos cotidianos o las decoraciones en los grutescos de Lucas Kilian (1579-1637).

Estos seres y sus mundos aparecen representados en cualquier formato, asî se puede crear toda una cosmología del híbrido simplemente estudiando, por ejemplo, los capiteles románicos en donde se esculpían los mensajes religiosos y morales para adoctrinar a un pueblo analfabeto y temeroso de Dios. Asimismo, en las decoraciones de manuscritos y códices o en las maravillosas cartografías como las que realizó Abraham Ortelius en el siglo XVI mostrando monstruos e híbridos marinos, que en esta época muchos creían que habitaban los mares.

En la pintura de cualquier época podemos encontrar a estos seres, por ejemplo, los artistas Willian Blake, inglés (1757-1827) o Paul Gustave Doré, francés (s. XIX). Representaron, cada uno a su manera, el Bosque de los Suicidas, re- 


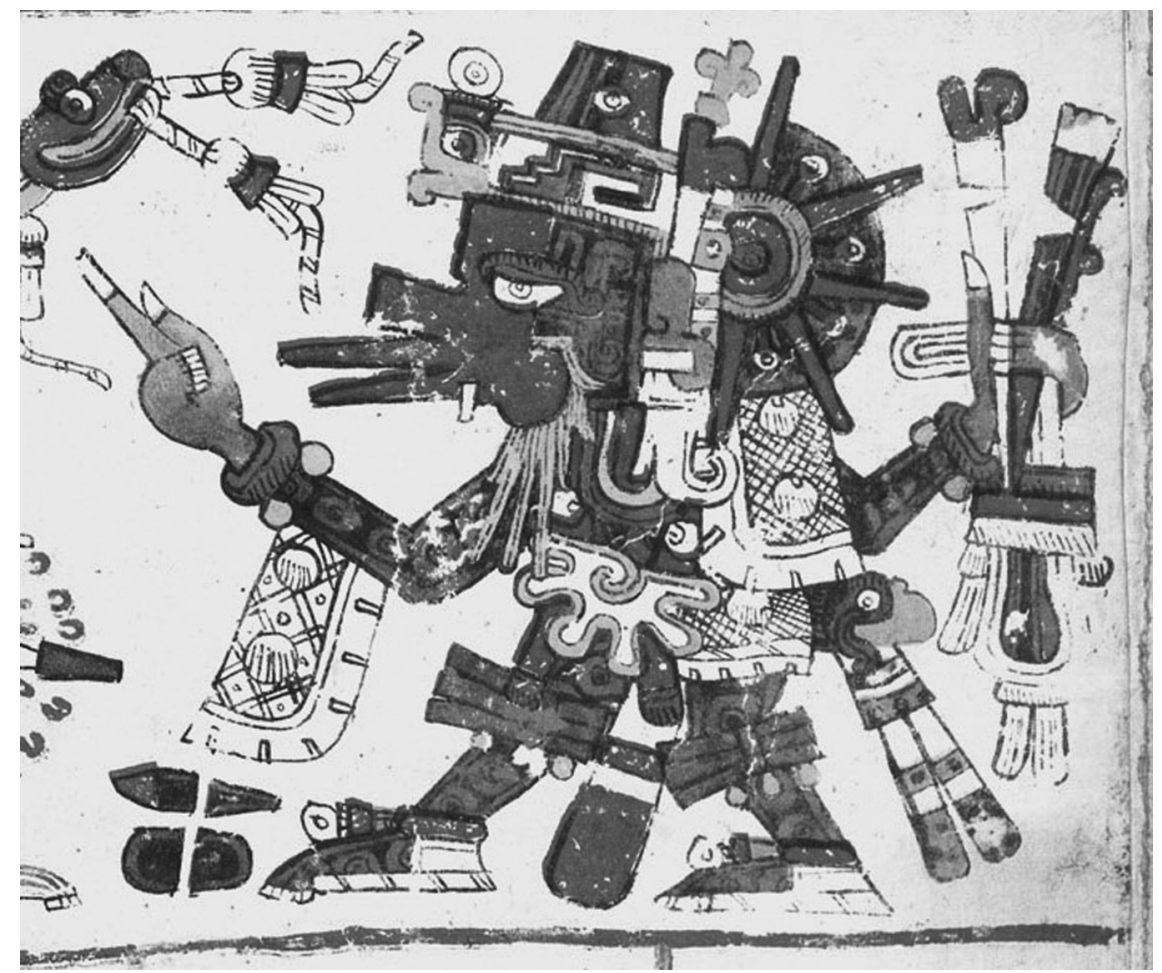

Figura 6. Quetzalcóatl en el Códice Borgia.
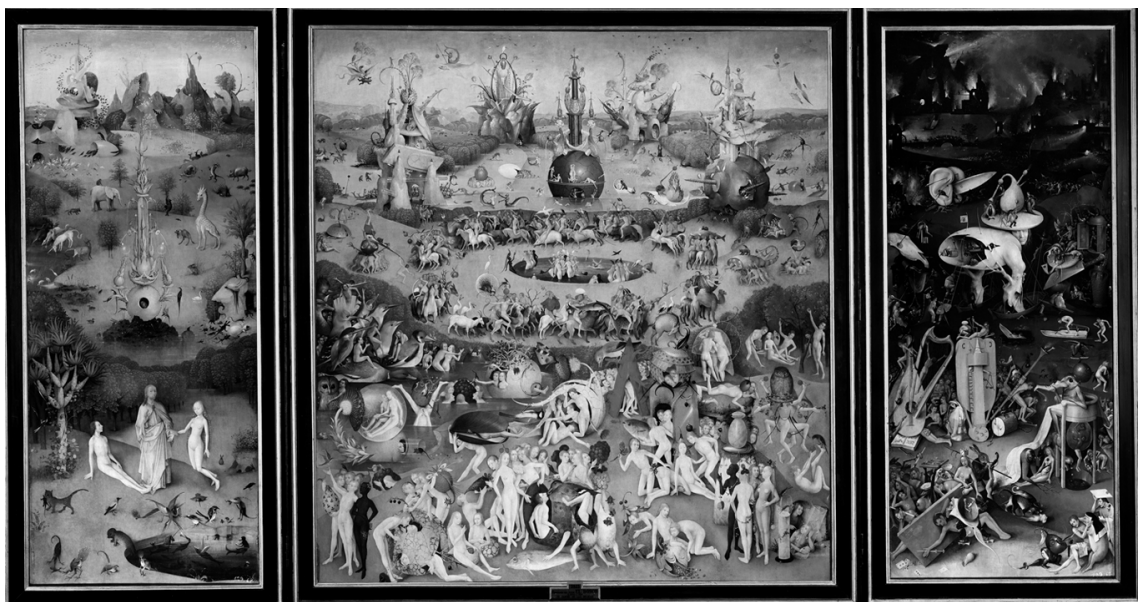

Figura 7. El Bosco. El Jardín de las Delicias. Museo del Prado. 


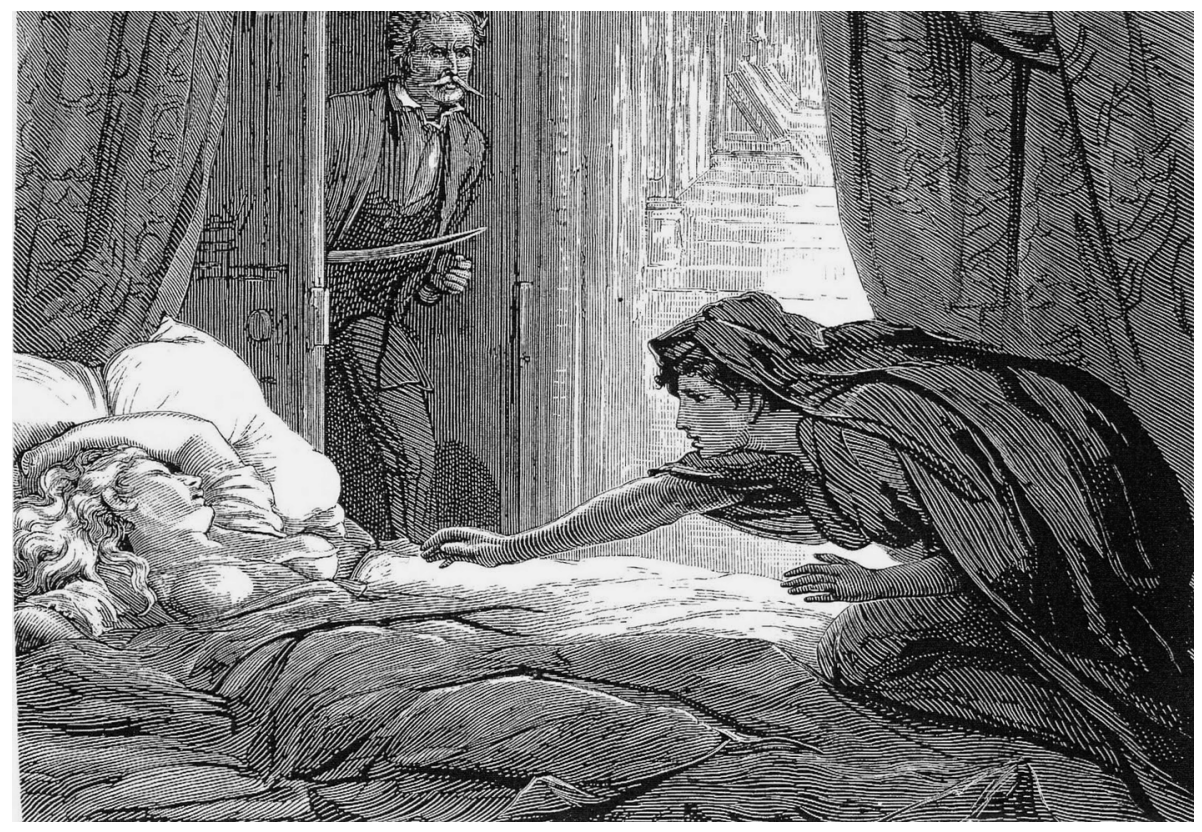

Figura 8. Ilustración de D.H. Friston de la primera publicación de Carmilla en la revista The Dark Blue en 1872.

pleto de seres grotescos, monstruos e híbridos (versos dentro de la obra literaria La Divina Comedia, escrita en el siglo XIV por Dante Alighieri). Leonardo da Vinci, italiano renacentista, incluso Francisco de Goya en sus Caprichos (s. XVIII), donde el artista representa una sátira de la sociedad española, trata de manera muy personal esta temática, dotándola de un sentido diferente, animaliza al ser humano creando un híbrido de ensoñación y pesadilla.

También en la literatura estos seres híbridos encuentran un campo de cultivo donde la creatividad del escritor/a puede dar rienda suelta sin límites. Personajes literarios como Carmilla, de Joseph Sheridan Le Fanu en 1872, forma parte de la literatura de terror gótico de la época y una de las primeras historias de vampiros escritas. Aunque evidentemente los vampiros entrarían en otro tipo de catalogaciones sobre monstruos de ultratumba, no podemos negar que adquiere una parte de híbrido, miscelánea entre la vida y la muerte, la nomuerta, entre dos mundos -el inframundo y el físico-, entre la ensoñación y la realidad. Pero sí encontramos, por ejemplo, en la mitología del folclore gitano y eslavo un híbrido entre vampiro (hombre/mujer) y humano. Siendo esto úl- 
timo el resultado de la concepción de un vampiro y una mujer terrenal o viceversa, considerado como un práctico cazador de vampiros. Evidentemente este personaje también ha sido carne de cañón en el mundo del arte, sobre todo en comics, series, películas y videojuegos.

Rescatando el comienzo de este capítulo, en donde hablábamos de la propia divinidad como ser híbrido, no debe extrañarnos que también lo sean el demonio, los ángeles caídos. Estos seres conforman una cosmología de híbridos representados del mismo modo en diferentes disciplinas artísticas. En el cine, el film El Exorcista (The Exorcist, William Friedkin, 1973), nos muestra ídolos demoníacos encontrados en excavaciones, figuras en apariencia inertes, pero que pueden albergar seres venidos del infierno para terror y horror del ser humano. Volviendo a la pintura, el óleo de Pieter Brueghel, llamado el Viejo, La caída de los ángeles rebeldes (1562), inspirado en el pasaje de Apocalipsis de la Biblia, donde nos muestra seres demoníacos mitad hombres, mitad animales, representando los conflictos entre el bien y el mal.

\section{EVOLUCIÓN DE SIGNIFICADOS Y FUNCIONES DEL SER HÍBRIDO EN PARALELO A LA PROPIA SOCIEDAD}

Adjudicamos a estos seres nuestros miedos, nuestros yerros, pecados, pero también nuestros ideales. Su aspecto los hace que aparezcan generalmente como monstruos. Intentamos apartarlos por lo que de negativo tienen, por lo de antinaturales, por lo de monstruoso, a veces intentamos controlarlos pues su acción para nosotros puede ser positiva. Aplicamos en ellos nuestra imaginación, nuestras faltas, nuestras virtudes, porque al reflejarnos en ellos vemos que en realidad somos nosotros mismos trasmutados.

La ciencia, la sociedad, ha ido superando esos mitos de la Antigüedad, ya no tienen un significado ni el grifo, ni la medusa, ni la esfinge. A la luz de la razón han desaparecido esas explicaciones míticas. El proceso ha sido largo, la civilización occidental ha ido asimilando los seres de la Antigüedad a nuevos paradigmas en la Edad Media, se asumen rasgos, características en una nueva narración y así cada momento histórico. Se trata de un proceso, de una refuncionalización de la narración. Pero seguirán siendo seres terribles, guardianes, violentos, o tal vez próximos, nobles.

Incluso, hasta qué punto no podemos considerar dentro de los seres que estamos tratando también el concepto de dualidad. Seres ambivalentes, el ser humano y su capacidad de ser más de uno. Hombre/mujer que puede ser la bondad y la maldad en un mismo cuerpo, es por ello imposible no referirse a la novela 
titulada El extraño caso del doctor Jekyll y el señor Hyde (1886) de Robert Louis Stevenson, la literatura está plena de seres que son una cosa y aspiran a otra. Ante la angustia de no saber quiénes somos, de dónde venimos y dónde vamos... y por ello creamos esos sueños, esas ilusiones, esas esperanzas que definan, que nos aseguren nuestra propia identidad o más bien que nos permita imaginarla.

Podríamos ver en las dualidades de Nietzsche (2007, 47 y ss.), una verdadera hibridación del ser humano en su mismo concepto. La interpretación de los dioses mitológicos griegos Apolo y Dioniso, dualidad confrontada y al unísono suplementaria. Por una parte, lo bello, la bondad, tal vez lo espiritual del ser humano y por otra lo terrenal, las apetencias de la carne; ambos aspectos reflejados según la visión de Nietzsche en los dioses griegos comentados. La unión de ambas tendencias, la hibridación, es la realidad del ser humano.

"Estos dos instintos tan diferentes caminan parejos, las más de las veces en una guerra declarada, y se excitan mutuamente a creaciones nuevas, cada vez más robustas, para perpetuar, por medio de ellas, ese antagonismo que la denominación 'arte', común a ellas, no hace más que enmascarar, hasta que, al fin, por un admirable acto metafísico de la voluntad helénica, aparecen acoplados, y en este acoplamiento engendran la obra, a la vez dionisíaca y apolínea, de la tragedia antigua" (Nietzsche, 2007, 47-48).

La voluntad helénica "los acopla" y crea una obra única, un ser único hecho de antagónicos.

\section{EL SER HUMANO JUGANDO A SER DIOS, CREADOR. ARTE, CIENCIA Y TECNOLOGÍA. EL CIBORG}

Pero no solo Dios o el más allá juegan a crear seres híbridos, también el ser humano ansía ese poder y experimenta, aquí la ciencia forma parte inherente e imprescindible de este mundo imaginado o no tan imaginado. La meta ya no es la hibridación entre animal y animal, ser y ser sino la quimera y el objetivo del híbrido humano-máquina.

Ya en la mitología de la obra literaria Frankenstein (1818) de la autora Mary Shelley, se da vida a un ser híbrido formado por diferentes partes de otros seres humanos, que en la novela no aparece el milagro de la electricidad y sí en los posteriores films cinematográficos.

El ser, el híbrido hombre-máquina será el ciborg. El término fue acuñado a principios de los años 60 del siglo XX por los doctores Manfred E. Clynes y Nathan S. Kline: "Para el organismo complejo, expandido de forma exógena y funcionando inconscientemente como un sistema homeostático integrado, proponemos el término Cyborg" (Clynes y Kline, 1995, 30). 
De manera sencilla, la idea hombre-máquina, el ciborg, no es solo una cuestión del siglo XX y XXI, siglos anteriores ya experimentaron con esta cuestión como un objetivo de superación. Si nos remontamos al siglo XVI, el énfasis de mejorar el cuerpo humano existe en Ambrosie Paré, padre de la cirugía moderna, considerado uno de los primeros especialistas en la creación y aplicación de prótesis. La mayoría de sus "artefactos" disponían de mecanismos internos que permitían su movilidad. Esta necesidad de mejora viene dada por los mutilados en guerra. U otros personajes como Frédéric Leschot (siglo XVIIIXIX), relojero que se especializa en construcción de prótesis de miembros amputados no solo reestructurando un aspecto estético si no también, y gracias a su profesión, desarrollando el grado de funcionalidad de estas prótesis. (Iglesias, 2016, 204-211).

En el siglo XVIII, Julien Offray de La Mettrie, médico y filósofo francés escribe el estudio El hombre máquina, donde defiende la presencia corporal como un mero cascaron automático.

Son conceptos muy cercanos al ciborg contemporáneo y las teorías, por ejemplo, de Donna Haraway y su ser liberador de género y ataduras sociales, en este último caso, un ser filosófico evolucionado. El ciborg aparece como un espacio desde donde pensar el feminismo en la década de los ochenta. En su texto Manifiesto para Cyborgs: ciencia, tecnología y feminismo socialista a finales del S. XX de 1985 dice: "A finales del siglo XX -nuestra era, un tiempo mítico-, todos somos quimeras, híbridos teorizados y fabricados de máquina y organismo; en unas palabras, somos cyborgs. El cyborg es nuestra ontología, nos otorga nuestra política. Es una imagen condensada de imaginación y realidad material, centros ambos que, unidos, estructuran cualquier posibilidad de transformación histórica" (Haraway, 1995, 254). El ciborg supera las dicotomías de la modernidad, no es necesario elegir una posibilidad entre la Mujer, el Hombre o el Otro. Haraway utiliza mucho la figura del monstruo o híbrido, es el Otro, que está siempre en oposición a las identidades clásicas. También puede mutar en una figura que promete la superación de la identidad (Adán, 2006, 182). Con este manifiesto se basa mucha de la cibercultura actual además de diversas narrativas feministas del siglo XX y XXI como hemos subrayado.

Haraway crea una metáfora con la utilización de la figura del ciborg para describir una estrategia política del socialismo y el feminismo. Juega con las diferentes definiciones de la figura de la mujer, no como agrupación de identidad sino creación de grupos, más bien, por afinidad. El ciborg no depende de una identidad esencialista. El ser humano hombre/mujer debería despojarse de ese sentido de identidad. Basándose en la creencia de que ya no existe el cuerpo ni la naturaleza, al menos en el sentido clásico y tradicional, ambos están contaminados filosóficamente en el momento que la tecnología entra a formar 
parte de nuestros "cuerpos". Como apunta Haraway, la situación de las mujeres se ve reestructurada profundamente por los cambios, implicaciones sociales y de la tecnología; arremeterá contra anteriores ideas feministas que defendían la metafísica anticientífica y una "demonización de la tecnología" ya que abocaría a una pérdida total del poder.

Pero respecto a ciborgs, el propio Leonardo Da Vinci investigó de qué manera acoplar a nuestros brazos unas alas y poder volar, recogido en el Códice de Turin, donde estudia sobre el vuelo de los pájaros, aunque Da Vinci acabó descubriendo que los brazos del ser humano no tienen la suficiente fuerza para batir el tipo de alas que ideó (Escarti, 2012). No obstante, ya este artistahumanista del Renacimiento evoca la posibilidad de, a través de una tecnología construida por el hombre, este adquiera unos "superpoderes", y transmute el cuerpo de manera híbrida para llegar a volar.

Stelarc, artista contemporáneo de nuestra época experimenta entre ciencia y arte con su Tercera Oreja, la superación de los sentidos del ser humano, no solo de manera propia, sino compartiendo sus experiencias de manera colectiva y a través del mundo digital, a través de las redes (http://stelarc.org/projects.php).

El artista utiliza su cuerpo como si fuese un objeto básico que ha de ser profundamente modificado por la máquina para acceder a un cuerpo ampliado y transhumano. (Duque, 2003, 174).

O la artista Natasha Vita-More con Primo 3M+ radical body design, un cuerpo que combina ingeniería estética con nanotecnología, piel artificial inteligente, inteligencia ampliada, y un cuerpo compuesto de partes reemplazables que se pueden actualizar, ampliar y optimizar. El ser humano se desprende de su mundo físico-anatómico para convertirse en un híbrido compuesto de diferentes piezas (http://www.natasha.cc).

La artista francesa Orlan y su eslogan "El cuerpo no es más que un disfraz", que, mediante sus operaciones estéticas en directo, por una parte, muestra la fuerza y poder del tratamiento de la mujer como objeto, como canon de belleza de un mundo de representación patriarcal hasta cómo nos convertimos en híbridos mediante implantes, bótox, creando otro ser diferente al primigenio. $\mathrm{Su}$ objetivo es llegar a ser la Mujer única, su finalidad es reproducir los elementos más bellos de las mujeres occidentales canónicas a lo largo de la historia del arte, "la frente de la Gioconda, los ojos de la Psique de Géromê, la nariz de una Diana de la Escuela de Fontenbleau, la boca de la Europa de Boucher y la barbilla de la Venus de Botticelli” (Dery, 1995, 265).

La evolución del imaginario, ya no ficticio sino más bien real del hombremáquina, lleva a paisajes digitales, inmersos en la virtualidad de unos y ceros. El ser humano se difumina, deja su cuerpo físico en un segundo plano para entrar en la Red, espacio en donde las leyes físicas trasmutan, un espacio liberador. 
Ese nuevo paisaje, el ciberespacio, término que aparece por primera vez en la novela El Neuromante, publicada en 1984, del autor William Gibson, en donde a través de nodos y cables entras en la máquina, formas parte de ella, la manipulas. Pero ella también te manipula, la mente humana se despoja del aspecto físico para desplazarse de manera virtual, aunque nuestra vida, nuestra mortalidad siga dependiendo del elemento biológico. Así se evoluciona, en estos casos, al concepto de posthumano de la teoría Transhumanista. Algunos de los filósofos y pensadores que componen esta corriente como Nick Bostrom definen esta teoría como "movimiento cultural, intelectual y científico que afirma el deber moral de mejorar las capacidades físicas y cognitivas de la especie humana, y de aplicar al hombre las nuevas tecnologías a fin de que se puedan eliminar los aspectos no deseados y no necesarios de la condición humana: el padecimiento, la enfermedad, el envejecimiento e, incluso, la condición mortal" (en Cortina y Serra, 2015, 18).

Pero la mala utilización de estas tecnologías, por parte del ser humano, pueden llegar a ser espeluznantes o distópicas. Las historias de ciencia ficción son caldo de cultivo para mostrarnos las múltiples situaciones que podrían acontecer en una época no muy lejana a nuestro contexto histórico. Ejemplos como el film Sleep Dealer (Alex Rivera, 2008), película de ciencia ficción, que como muchas otras asusta su posible realidad, en donde cuestiones como la inmigración se solucionan conectando a trabajadores desde México, a través de nodos a una red informática, para que manipulen maquinaria de construcción en EE.UU bajo precariedad y trabajo esclavista. O series como Black Mirror (2011-2019), creada por Charlie Broker y producida por Zepporton en Reino Unido y EE.UU. Algunos de sus capítulos narran la distopía de poder visionar tus recuerdos, no solo tú, sino los que te rodean, haciendo colectivo un elemento personal, llegando a cambiar el concepto de relaciones sociales y el derecho a la propia privacidad individual (The Entire History of You, 2011 y Crocodile, 2017).

Como observamos la literatura y el cine nos regalan infinitos personajes ciborgs, por enumerar algunos, uno de los más conocidos y con mayor éxito es el film RoboCop (Paul Verhoeven, 1987). Obtuvo tanto éxito que generó diversas secuelas, comics, una serie para televisión, videojuegos, etc. Nos describe un policía justiciero contra las grandes empresas, en sus historias trata temas tan actuales a día de hoy como la gentrificación, la masculinidad, la privatización, la manipulación mediática... Este ciborg se crea a partir del cuerpo sin vida de un policía y elementos robóticos, nos recuerda su creación a la manera Frankenstein. 


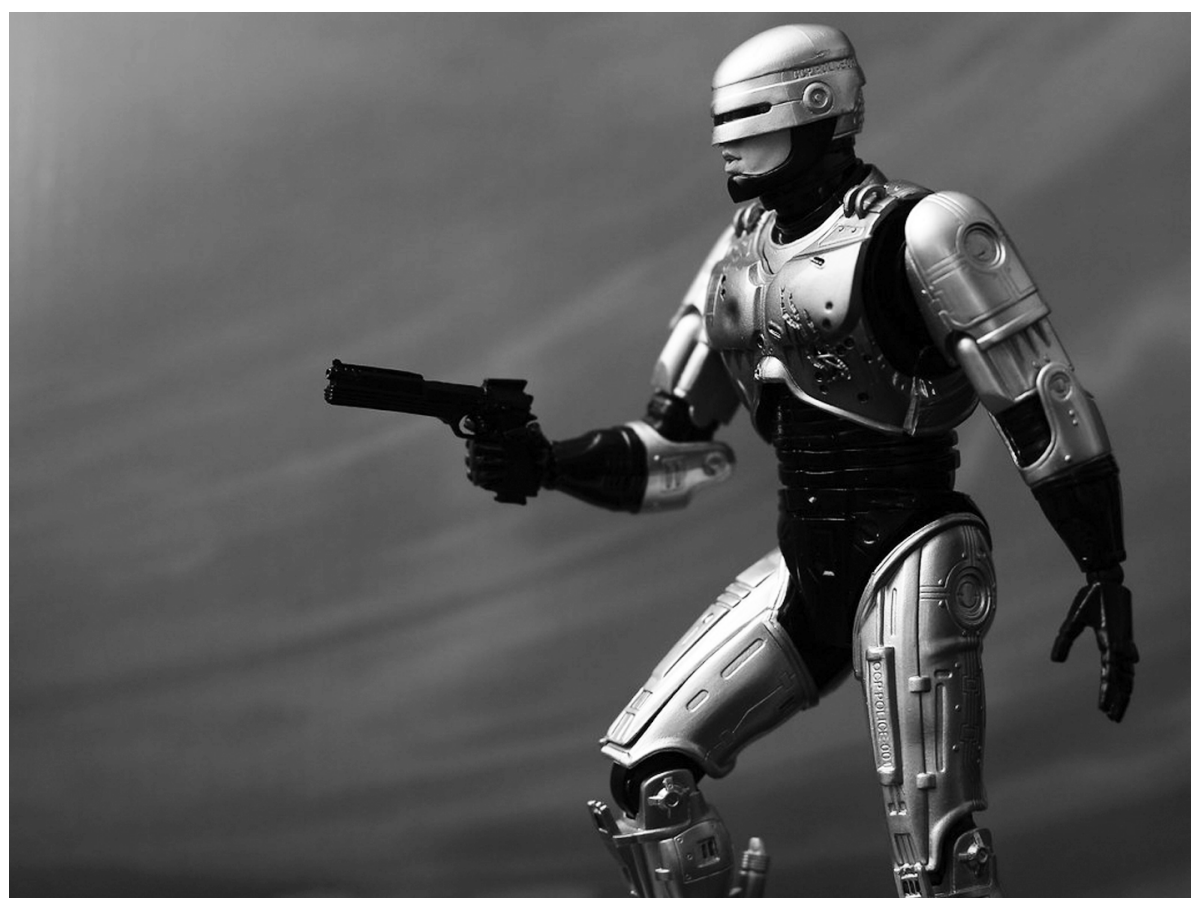

Figura 9. Representación del personaje de ficción Robocop.

Otras hibridaciones, de las cuales todavía no hemos hablado, humanoextraterrestre, extraordinariamente representadas en la saga Alien, más concretamente en Alien: resurrección (Jean Pierre-Jeunet, 1997). En donde no solo se clona a la protagonista, Ellen Ripley, si no que, y no por decisión humana si no por un error, se mezcla el ADN de la humana con la del alien o extraterrestre creando una supermujer, con una fuerza sobrehumana.

Tron (Steven Lisberger, 1982) y su reciente secuela Tron: Le gacy (Joseph Kosinski, 2010), que nos reconduce de nuevo al mundo del ciberespacio, del cual hemos hablado anteriormente, esta película nos describe un viaje por los circuitos de una computadora donde los programas tienen vida y personalidad propia, generando una retro-alimentación entre lo "material" y lo "inmaterial" (Dery, 1998).

Estamos recorriendo un imaginario, un mapa de diferentes ciborgs ficticios visto desde el arte, pero no debemos obviar que este ímpetu por llegar a sobrepasar las posibilidades físicas y mentales del humano contemporáneo es algo 
que está en primer plano en nuestra realidad y en ocasiones preocupante. La búsqueda del ciborg atleta, a través de anabolizantes, todo tipo de drogas, trampas... verdaderas quimeras. La genética ya ha permitido la síntesis de la célula humana con la de otras especies, serán los híbridos citoplásticos, cybrids (de Miguel Beriain, 2011, 101). Si bien los resultados hasta el momento han sido negativos, todo ello nos plantea unas problemáticas muy acusadas y no hablamos solo a nivel técnico, sino especialmente moral.

\section{CONCLUSIONES}

A través de la hibridación, o merced a ella, podremos llegar a lo que Nietzsche planteaba como el superhombre (übermensch):

"Ésta es mi duda respecto a vosotros y mi secreto reír; ¡apuesto a que a mi superhombre lo llamaréis demonio!

Ay, me he cansado de estos hombres, los más elevados y los mejores de todos: desde su "altura" sentí yo deseos de marchar hacia arriba, lejos, fuera, ¡hacia el superhombre!” (Nietzsche, 2003).

A lo largo de la historia el ser humano se ha rodeado de una cosmogonía de seres híbridos, en un principio seres mitológicos para entender el origen del mundo que le rodea, en otras ocasiones como necesidad para dar respuesta a tantas incógnitas y misterios que rodean el sentido de nuestra propia vida. Les hemos proveído del poder tanto protector como destructor, dejando así la responsabilidad de juzgar nuestros actos a seres divinos y mágicos. Pero la civilización evolucionará y sentirá la necesidad de convertirse ella misma en divinidad y controlar esos poderes delegados con anterioridad. El hombre ansiará ser el propio creador, la naturaleza ya no dominará, sino que será dominada o por lo menos, se intentará.

¿Hemos llegado, en estos tiempos nuestros, a la hybris griega? A la desmesura, a la confianza plena en nosotros mismos, ¿somos la cumbre, el poder de transformar la Naturaleza, de transformarnos a nosotros mismos? ¿Hemos superado el caos de la razón? Esta desmesura, este engreimiento, ya no solo nos compara con los dioses a los que hemos matado, sino que nos pone ante el fin de la Historia. ¿Es esto un mero espejismo, uno más del fin de los tiempos, del Apocalipsis, de una nueva Era? La tecnología nos pone en situación de plasmar no pocas de nuestras imaginaciones, de nuestros deseos más ocultos, de nuestra ansia de eternidad, y aquí aparece la ética, la buena utilización de las herramientas dadas a lo largo de los siglos. Pero que tire la primera piedra el o la que en algún momento de debilidad no ha sentido la tentación de pasar al lado oscuro, porque tanto Darth Vader como Luke Skywalker fueron ciborgs, fueron híbridos. 


\section{BIBLIOGRAFÍA}

ADÁN, C. (2006): Feminismo y conocimiento. De la experiencia de las mujeres al ciborg, La Coruña, Edicións Espiral Maior.

ALIGHIERI, D. (1921): La Divina Comedia, Barcelona, Casa Editorial Maucci.

CLYNES, M., KLINE, N. (1995): “Cyborgs and Space”. En The Cyborg Handbook. Nueva York y Londres, Routledge.

CORTINA, A., SERRA, M. (2015): ¿Humanos o posthumanos? Singularidad tecnológica y mejoramiento humano, Barcelona, Fragmenta.

DE LA METTRIE, J. O. (2014): El hombre máquina, el hombre planta y otros escritos, Madrid, Akal.

DE MIGUEL BERIAIN, I. (2011): “Quimeras e híbridos: ¿Problema ético o problema para la ética?", Dilemata, no. 6, 101-122.

DERY, M. (1998): Velocidad de Escape. La cibercultura en el final de siglo, Madrid, Siruela.

DUQUE, F. (2003): “De cyborgs, superhombres y otras exageraciones”, en: Hernández, D. (Ed), Arte, Cuerpo, Tecnología, Salamanca, Ediciones Universidad Salamanca.

ESCARTI, F. (2012): El secreto de los pájaros, Granada, Ediciones Dauro.

ESTEBAN SANTOS, A. (2013): Iconografía de la Mitología griega. Monstruos. Los terroríficos enemigos del héroe (monstruos, híbridos y otros seres fantásticos), Madrid, Dhyana Arte.

GIBSON, W. (2014): Neuromante, Barcelona, Editorial Planeta.

GRIMAL, P. (1997): Diccionario de mitología. Griega y romana, Barcelona, Ed. Paidós Ibérica.

IGLESIAS, R. (2016): Arte y robótica. La tecnología como experimentación estética, Madrid, Casimiro.

IZQUIERDO, I., MEAUX, H. (coords.) (2003): “Seres híbridos. Apropiaciones de motivos míticos mediterráneos", Actas del Seminario Exposición, Casa VelázquezMuseo Arqueológico Nacional, Madrid, 7-8 de marzo de 2002.

HARAWAY, D. (1995): Manifiesto para Cyborgs: ciencia, tecnología y feminismo socialista a finales del $S$. XX, Valencia, Universitat de València.

HOMERO. (1991): Odisea, Madrid, Espasa-Calpe.

MALAXEVERRÍA, I. (1999): Bestiario medieval, Madrid, Siruela.

MONTESINOS I MARTÍNEZ, J. (2002) "Sobre una escena de hombre-ciervo en la Terra Sigillata Hispánica”, Ars Longa, 11, 7-15.

MORRIS, I. (2007): Historia y cultura. La revolución de la arqueología, Barcelona, Edhasa, 422-423.

NIETZSCHE, F., (2003): Así habló Zaratustra, Madrid, Ed. de Andrés Sánchez Pascual, Alianza Ed.

NIETZSCHE, F. (2007): El origen de la tragedia, Austral Ciencias Humanidades, Madrid, Espasa Calpe. 
OLMOS ROMERA, R. (2003): "Seres de nuestra sinrazón y nuestros sueños", en Izquierdo, Meaux, Seres híbridos. Apropiaciones de motivos míticos mediterráneos, Actas del Seminario Exposición, Casa Velázquez-Museo Arqueológico Nacional, Madrid, 7-8 de marzo de 2002, 29-36.

SHELLEY, M.W. (2007): Frankenstein o el moderno Prometeo, Madrid, Cátedra.

SHERIDAN LE FANU, J. (2003): Carmilla, València, Brosquil.

STELARC. http://stelarc.org/projects.php [Consulta: 7 de octubre de 2019].

STEPTOE, P.C., EDWARDS, R.G. (1978): "Birth after the implantation of a human embryo", Lancet, $\mathrm{n}^{\circ} 2$.

STEVENSON, R.L. (2006): El extraño caso del doctor Jekyll y el señor Hyde, Madrid, Valdemar.

YUSHIMITO DEL VALLE, C. (2010-2011): “Del prodigio de Rávena al Guzmán de Alfarache. Una lectura de la monstruosidad del cuerpo social picaresco en el contexto didáctico de la Contrarreforma", Espéculo. Revista de Estudios Literarios, 46, http://www.ucm.es/info/especulo/numero46/guzmanal.html [Consulta: 7 de octubre de 2019].

VITA-MORE, N. https://natashavita-more.com/ [Consulta: 7 de octubre de 2019]. 